\title{
Un Kant contemporáneo y necesario
}

\author{
Resenã de Voluntad omnilateral y finitud de la \\ tierra. Una lectura de la filosofía política de Kant, \\ de Macarena Marey (Adrogué, La Cebra, 2021)
}

\author{
Marcos Travaglia \\ m.travaglia@conicet.gov.ar \\ (Universidad de Buenos Aires - CONICET, Buenos Aires, Argentina)
}

DOI: http://dx.doi.org/10.11606/issn.2318-9800.v26i1p65-72

La filosofía política de Kant es, para el lego, un terreno poco conocido. De forma similar a lo que dice la famosa metáfora de la Crítica de la razón pura (A236=B295), nos quedamos en los límites seguros de la imponente isla de su filosofía teórica y las primeras rocas de algunos de sus textos prácticos y no salimos de allí. No sabría juzgar si es nuestra razón la que no desea ir más allá, o si son las monótonas lecturas que aprendemos en los cursos básicos los que nos disuaden de lanzarnos a las más agitadas aguas de obras como Religión dentro de los límites de la mera razón (RGV, 1793) o Metafísica de las costumbres (MS, 1797).

En Voluntad omnilateral y finitud de la Tierra. Una lectura de la filosofía política de Kant Macarena Marey nos ofrece una estimulante interpretación de este otro Kant. La autora, doctorada por la Universidad Nacional de La Plata y desde entonces becaria posdoctoral e investigadora del CONICET y docente de diversas 
universidades, presenta una condensación de su itinerario kantiano. A lo largo de estas páginas ofrece una visión de conjunto y unificada de los últimos años del itinerario filosófico de Kant - así como de sus últimos años leyéndolo.

La obra sigue un camino de una introducción y siete capítulos que comienzan con la fundamentación metafísica de la política, la moral y la ética para dar paso a una teoría de la justicia. Marey establece varios niveles de discusión que hacen a la complejidad del libro: dialoga con Kant, con las lecturas de Kant de otrxs filósofxs (Hobbes, Rousseau, Grocio, etc.) y con los debates que estas interpretaciones kantianas han generado en la contemporaneidad. La precisa arquitectura del argumento requiere tener estos niveles en cuenta pues - con fiel espíritu crítico ninguno de ellos se salva de rendir cuentas de su pretensión de validez.

La Introducción consta de dos partes. La primera explicita de forma sucinta y clara las tesis y posiciones articulan los capítulos subsiguientes. Se trata de un conjunto de afirmaciones que no solo matizan muchas ideas en torno a un Kant liberal europeo clásico, sino que hasta la ponen en jaque. La segunda expone un manifiesto filosófico, sentando su posición sobre qué es hacer historia de la filosofía filosóficamente. Así, recupera un linaje de lectoras y lectores - con quienes dialoga página a página - que se apropian de Kant con dos condiciones que son aquellas que definen su postura sobre la historia filosófica de la filosofía: la fidelidad al sistema y la apropiación significativa para problemas de interés e importancia contemporánea (Bertomeu, Sánchez Madrid, Rivera Castro, O’Neill, Flikschuh, Maus, etc.). Repasa y cuestiona también brevemente sus críticas a interpretaciones bien establecidas (Rawls, Arendt, Habermas, Foucault, etc.). Además, afirma que no pretende dar una lectura definitiva de la filosofía política kantiana, pero sí una que "es bueno sostener y defender de manera sistemática por sí misma" (p. 23). No se trata de una mera exégesis sino de una intervención en un campo filosófico y práctico, como se evidencia en los últimos capítulos.

El capítulo 1, "Moral, ética y derecho en Kant: una cuestión política", se trata de que el derecho, la ética y la moral se derivan de la noción de comunidad ética. Para Kant la respuesta al mal radical no está en cada consciencia individual, sino en la articulación polifónica de las subjetividades. La noción central del capítulo es la de derecho. Para Marey su fundamentación no es un contrato de voluntades individuales (pero aún así depende de la voluntad popular) ni parte de la libertad negativa (sino de la positiva). En el apartado "Derecho" entonces discute estas líneas para defender que el concepto de derecho implica una articulación entre coacción y libertad con una controvertida (o contraintuitiva) tesis: la coacción no es monopolio de violencia legítima del Estado, sino la acción del Estado que sostiene la correlación 
entre derechos y deberes jurídicos promoviendo y garantizando la libertad externa de todas las personas. Luego pasa a la discusión de Kant con Hobbes y Rousseau. Contra Hobbes, sostiene que el derecho debe ser moral. Para Kant, Hobbes sostiene que la salida del estado de naturaleza es un medio para el fin último de la felicidad. El problema está en que para Hobbes la obligación jurídica no se funda en algo universal sino en un fin individual (y unilateral) y no puede justificar ni el ingreso en el Estado ni la coacción. El fin del derecho no puede ser la felicidad, sino el derecho mismo. Contra Rousseau, Kant rechaza que el derecho se funde en una voluntad general que nace de las buenas voluntades internas de los ciudadanos y su identificación en el bien común compartido, sino que debe restringirse a la libertad externa para mantenerse moral (y no volverse ética). De esta forma, ética y derecho dependen de la moral en su sentido normativo, y así, dice Marey, en la filosofía jurídica y política moderna moralmente permisible equivale a legítimo.

A continuación, el breve capítulo 2 trata "Sobre el carácter externo y normativo de los deberes jurídicos: por qué Kant puede tenerlo todo” y, como indica su título, continúa la caracterización del capítulo anterior sobre el derecho para mostrar cómo Kant desarrolla un concepto de deber jurídico externo y moral (i.e., normativo). En una primera vía argumental aborda los conceptos de moral e imperativo categórico para mostrar cómo en la década de 1790 estos conceptos ya no se restringen a la ética como en la de 1780. Así, la autora reconstruye en base a la MS que el derecho es moral porque se refiere sólo a cuestiones externas entre las personas. Entonces analiza la relación entre el derecho y el imperativo categórico bajo la línea de la doctrina de la virtud (ética) y la del derecho (moral): en ambos casos se trata de un indicador de que una acción u omisión es un deber, pero determinados por dos tipos de legislación distinta. La “ley universal” interna y ética es definida por un sistema distinto de la "ley universal” externa y del derecho, pero en ambos casos lo que demuestra es que refiere a la libertad humana y su capacidad de coaccionarse a sí misma. En la segunda vía, Marey propone que la normatividad jurídica surge de la reciprocidad que hace a la igualdad innata que permite la libertad externa y hace necesarias las comunidades políticas. Aquí tenemos un primer acercamiento al contractualismo kantiano (del que se ocupará en detalle el capítulo siguiente). La obligación jurídica no surge, como en otras teorías de la época, de las motivaciones racionales subjetivas sino por la reciprocidad: A reconoce que $\mathrm{x}$ es propiedad de $B$ porque hay una garantía universal recíproca de que lo propio de A será reconocido por $\mathrm{B}$, que está en que para obligar a otra persona debo obligarme a mí por la misma norma. El corazón de esta respuesta está en la igualdad innata entre los seres humanos, que inevitablemente compartimos la tierra y requerimos de una 
normatividad que nos ordene. De esta forma, la externalidad y la normatividad están aseguradas para Kant en tanto se fundan en la libertad, específicamente en su nota de igualdad innata, que funda el derecho.

El capítulo 3 ("El exeundum kantiano, el derecho privado y la coacción") ingresa de lleno en el contractualismo, específicamente en la salida del estado natural y la polémica en torno al $\$ 42$ de la Doctrina del derecho. Se trata del capítulo más complejo del libro, que sigue un argumento muy fino de presentación y discusión de textos kantianos e interpretaciones recientes y solo repondremos las tesis que entendemos centrales. Marey señala que dicha polémica surge por la aparente contradicción entre que la necesidad práctica del exeundum se siga de los problemas propios del estado natural y que forman el derecho privado y que a su vez pueda derivarse analíticamente del concepto de derecho, que para Kant es anterior al estado natural y el derecho privado. La autora mostrará in extenso cómo no hay tal contradicción y que combinadas conforman un argumento normativo. Primero discute las hipótesis del "contractarianismo radical" (Hobbes: la normatividad proviene de actos individuales voluntarios, por lo que la necesidad de una autoridad política no puede presuponer normatividad ni sociabilidad previa; la normatividad se hace necesaria por los conflictos del estado natural) y del contractualismo superfluo (Rousseau: la normatividad es independiente de los actos individuales voluntarios, por lo que el contrato no genera normatividad sino que esta es previa). El exeundum es moral, no instrumental ni individual. Ni la tesis del mal radical ni las naturalezas individuales tienen un rol central aquí pues, como dice Marey, "La violencia es esa pretensión unilateral de imponer deberes sin conceder derechos" (p. 104, destacado de la autora). Esto es, la violencia es una imposición y no una obligación coactiva. El exeundum entonces debe partir de la igualdad y la reciprocidad entre las personas (en palabras de Kant, de la "coexistencia inevitable") que hace corresponder el deber de salir del estado de naturaleza con el derecho a coaccionar a las demás para que lo hagan también. El exeundum toma así la forma de una voluntad omnilateral.

El capítulo 4, "El carácter ideal de la voluntad general y la soberanía popular en Kant”, aborda la cuestión de la unidad del cuerpo político, que según Marey Kant fundamenta en la voluntad omnilateral y unificada a priori. En su primera sección la autora reconstruye el planteo del problema de como la necesidad de justificar cómo la unidad del cuerpo político da cuenta de (1) su artificialidad, (2) su composición por una multiplicidad de voluntades individuales unidas o reunidas, (3) la generación de una unidad en base a la multiplicidad. Hobbes y Rousseau dan las respuestas paradigmáticas más leídas por Kant, con diferencias diametrales en torno a (3), que ven o como una unidad posterior al exeundum encarnada en el soberano, 
o como una asociación de alienación total a una voluntad general que supera el egoísmo individual. La sección II reconstruye la posición kantiana sobre el tema (la voluntad general es ideal y necesaria a priori) frente a Flikschuh y Maus. La primera (con quien construye más fuertemente la discusión) sostiene, en pocas palabras, que para Kant no hay una autogénesis de la voluntad, que su idealidad es mental (y no regulativa) y que no logra vincularla con la praxis. Marey señala numerosos problemas de su interpretación en contradicción directa con pasajes de MS y RGV y la consecuente distancia entre Kant y Hobbes al respecto: el soberano es el pueblo, no el representante. Maus da una lectura más afín que le sirve para especificar el sentido de idealidad y necesidad a priori: la voluntad general es un ideal y en su unidad formal previa estructura el procedimiento de creación del derecho positivo y lo legitima. Marey sostiene que esta idealidad hace que solo exista en prácticas concretas de los agentes políticos y no una idea en la mente del gobernante. Luego desestima el problema de si la voluntad general puede esconder una voluntad de todos, i.e., intereses egoístas, retrotrayéndose a la omnilateralidad (rasgo central para Kant y que la hace popular). La sección III explica la tesis de que para Kant la unidad del soberano se funda en la voluntad omnilateral unificada a priori, por la cual las personas estamos mutuamente condicionadas por el hecho de la convivencia en un mismo lugar y que antecede toda pretensión de voluntades particulares cimentando el marco para su legitimidad. La última sección responde a posibles objeciones.

El capítulo 5, “La soberanía popular como principio suprajurídico. Igualdad soberana, omnilateralidad, comunidad de la tierra e interacción", parte de este concepto de soberanía como voluntad omnilateral y momento fundamental del derecho y desarrolla sus efectos derivados en el derecho estatal, internacional de gentes y cosmopolita. Empezamos a ver bien patente el sentido de la historia de la filosofía de la autora: no se trata de pensar solamente problemas para el siglo XVIII sino también para el mundo globalizado contemporáneo en el cual las democracias (formales o reales) se ven asediadas por el capitalismo transnacional y desigualdades de todo tipo (por esto mismo, la discusión alcanzará a teóricos del estatismo, el liberalismo y el cosmopolitismo contemporáneos que se nutren de Kant). Para Marey la noción kantiana de soberanía popular (ideal normativo, popular y adscrito al poder legislativo) permite “elaborar un sistema transnacional de derecho para contrarrestar las condiciones del orden internacional vigente, que sólo benefician a los países de altos ingresos y perjudican al resto del mundo" (p. 171) en tanto regula las tres esferas del derecho público (que deben estar coordinadas) y no se equipara al ejercicio de la violencia legítima sino a la correspondencia entre derechos y deberes. Al corazón de este capítulo está la tesis de que la coordinación de los tres niveles del 
derecho como comunidades políticas omnilaterales es la condición para revertir la iniquidad e injusticia estructurales y mantener relaciones que no sea de fuerza sino de correspondencia. En las siguientes secciones especifica la construcción del Estado con soberanía popular con la omnilateralidad como fuente de legitimidad de las normas jurídicas (II), su alcance transnacional (III) y por qué esta idea de soberanía no es equivalente a la fórmula clásica del monopolio de la violencia legítima (IV). II recorre extensamente una serie de temas hilvanados: la justificación del contrato social, la posesión común originaria de la tierra y las relaciones de propiedad, la fundamentación de la soberanía popular en la omnilateralidad y los principios de externalidad, correlatividad entre deberes y derechos, igualdad y posesión común, mientras que en III deriva del concepto de soberanía la defensa de la igualdad entre pueblos y la autonomía de los Estados frente a otros Estados o poderes paraestatales y otros tópicos como las ligas de Estados y la guerra en Hacia la paz perpetua. Es difícil sintetizar todas las derivas argumentales y reflexivas que se abren en este capítulo que cumple no solo una función de presentación y ampliación de conclusiones anteriores y corolarios derivados, sino además una intervención en numerosos debates actuales, importantes y urgentes. En este sentido, lo considero un insumo clave para disparar nuestras discusiones sobre cómo desarrollar eticidades que modifiquen las instituciones vigentes en un sentido igualitario y justo.

"Una teoría crítica de la propiedad", el capítulo 6, se centra en un tema que estuvo flotando durante todo el libro: la Tierra es finita y el compartirla determina nuestras relaciones de propiedad, más que generalmente injustas. El gran interlocutor en este tema es Grocio, en la medida en que para Kant la posesión originaria no es una premisa empírica sino un principio que permite evaluar la legitimidad de las pretensiones de propiedad. Como el capítulo anterior, este vuelve a resaltar argumentos kantianos útiles para defender un orden social justo. Kant, dice Marey, no pudo ver los efectos igualitarios (y no liberales) de su teoría: la vivienda es un derecho básico que obliga a que todas las personas posean una mientras que la acumulación desmedida de propiedades es ilegítima y no admite una justificación a la Locke del colonialismo o el imperialismo. Para Kant, sigue Marey, la propiedad privada no es un derecho absoluto y por ello las relaciones de propiedad son modificables en pos de la justicia social. La sección II reconstruye en tres pasos la crítica de Kant a Grocio. Primero, muestra cómo Kant avanza de la justificación del derecho absoluto a la propiedad de Grocio (un don divino para el hombre, centro de la creación) al derecho surgido de la pretensión de generar obligaciones recíprocas en otros al apropiarnos de algo. En adelante, Marey critica los déficits de la teoría de Grocio para garantizar, fundamentalmente, los derechos de las personas desposeídas. En este sentido, en 
la sección II. 3 vuelve a emerger un tema de imperiosa actualidad: justificaciones del derecho como la grociana permiten al Estado endeudarse o entrar en guerra de forma unilaterial y en perjuicio de los súbditos. Estos súbditos afectados, como bien señala Marey, no suelen ser clases privilegiadas sino sectores populares, subalternos, históricamente oprimidos y excluidos, que son golpeados ahora una vez más por razones de Estado y un presunto bien público del que no ven ni migajas. En el último apartado propone, en diálogo con Walla, Sánchez Madrid y Bertomeu, que la equidad como derecho fundamental que permite sortear los problemas anteriores porque da lugar a apelar ante injusticias y a crear derechos de bienestar social cuestionando la absolutización del de propiedad, todo en base a la fundamentación onmilateral y recíproca.

El último capítulo, "Una ética política”, ofrece una lectura de la comunidad ética de la RGV como una respuesta a una realidad social estructurada entre injusticias y males que facilita y se retroalimenta de acciones humanas egoístas. La comunidad ética es una eticidad que apunta a un mundo menos injusto formando subjetividades que reaccionen ante el mal radical. En la primera sección, Marey repone la naturaleza del mal radical como un problema social que requiere una respuesta también social, pensada en función de dicha realidad y las interacciones que permite. En este sentido, contra Guyer, la autora sostiene que la comunidad ética es un avance respecto de nociones éticas de los 80's y que tiende a la virtud común (no solo individual, pues el mal del arbitrio libre es inerradicable) y así a una transformación estructural de la sociedad. "Religión” en este contexto refiere a la esperanza de que podemos hacer algo frente al mal, no está pensada desde las instituciones sino desde los deberes contraídos y considerados como divinos. Así, en vistas de que Kant era anticlerical (y critica la pretensión normativa de las iglesias) y no hace una teología política, el lenguaje religioso sirve para disputar sentido con quienes utilizan la religiosidad popular con fines reaccionarios ( $\mathrm{y}$ en este sentido, resuena el auge de estos credos en Latinoamérica) en pos de la justicia. Marey habla de esto como de una ética política (no es del fuero interno, sino una que sólo existe en y a través de comunidades) y religiosa ("la religión kantiana es una eticidad política anticlerical y popular, pensada como condición que promociona la justicia en el mundo", p. 307).

Voluntad omnilateral y finitud de la tierra no es un libro fácil, pero sí es claro y ordenado. Sus argumentos son complejos, de reconstrucción precisa, y las posiciones y críticas son explícitas. Eso, sumado a una redacción fluida y un paso firme, permiten penetrar en la complejidad de los problemas tratados. Como último comentario, un gran valor del argumento del libro es que a partir del capítulo 1 se va construyendo 
un andamiaje teórico que comienza de forma muy abstracta pero se va volviendo cada vez más concreto, actual, vigente y necesario. A medida que el argumento se cristaliza más, tanto más se vuelven patentes los problemas contemporáneos que preocupan a Marey, pero también a un Kant que se nos revela republicano y popular. Estas reflexiones políticas son instrumentos con los que pensar y recursos con los que desarrollar respuestas efectivas a los sólidos entramados institucionales que garantizan más injusticias que ejercicios plenos de derechos. Celebro la publicación del libro de Macarena Marey y auguro que producirá un impacto duradero y será un material ineludible en las discusiones hispanoamericanas sobre la filosofía práctica kantiana.

Recebido em: 07.05.2021 